\title{
Oral Cannabidiol does not Alter the Subjective, Reinforcing or Cardiovascular Effects of Smoked Cannabis
}

\author{
Margaret Haney*,I, Robert J Malcolm², Shanna Babalonis ${ }^{3}$, Paul A Nuzzo ${ }^{3}$, Ziva D Cooper', Gillinder Bedi', \\ Kevin M Gray ${ }^{2}$, Aimee McRae-Clark ${ }^{2}$, Michelle R Lofwall ${ }^{3}$, Steven Sparenborg ${ }^{4}$ and Sharon L Walsh ${ }^{3}$ \\ 'Division on Substance Abuse, New York State Psychiatric Institute and the Department of Psychiatry, Columbia University Medical Center, \\ New York, NY, USA; ${ }^{2}$ Medical University of South Carolina, Charleston, SC, USA; ${ }^{3}$ University of Kentucky, Lexington, KY, USA; ${ }^{4}$ National Institute on \\ Drug Abuse, Bethesda, MD, USA
}

Cannabidiol (CBD), a constituent of cannabis with few psychoactive effects, has been reported in some studies to attenuate certain aspects of $\Delta^{9}$-tetrahydrocannabinol (THC) intoxication. However, most studies have tested only one dose of CBD in combination with one dose of oral THC, making it difficult to assess the nature of this interaction. Further, the effect of oral CBD on smoked cannabis administration is unknown. The objective of this multi-site, randomized, double-blind, within-subject laboratory study was to assess the influence of CBD $(0,200,400,800 \mathrm{mg}$, p.o.) pretreatment on the reinforcing, subjective, cognitive, and physiological effects of smoked cannabis (0.0 (inactive), 5.30-5.80\% THC). Non-treatment-seeking, healthy cannabis smokers ( $n=31 ; 17 \mathrm{M}, 14 \mathrm{~F}$ ) completed eight outpatient sessions. CBD was administered 90 min prior to cannabis administration. The behavioral and cardiovascular effects of cannabis were measured at baseline and repeatedly throughout the session. A subset of participants $(n=8)$ completed an additional session to measure plasma CBD concentrations after administration of the highest CBD dose (800 mg). Under placebo CBD conditions, active cannabis ( I) was self-administered by significantly more participants than placebo cannabis and (2) produced significant, time-dependent increases in ratings of 'High', 'Good Effect', ratings of the cannabis cigarette (eg, strength, liking), and heart rate relative to inactive cannabis. CBD, which alone produced no significant psychoactive or cardiovascular effects, did not significantly alter any of these outcomes. Cannabis self-administration, subjective effects, and cannabis ratings did not vary as a function of CBD dose relative to placebo capsules. These findings suggest that oral CBD does not reduce the reinforcing, physiological, or positive subjective effects of smoked cannabis.

Neuropsychopharmacology (2016) 4I, 1974-1982; doi:I0.I038/npp.20I5.367; published online I0 February 2016

\section{INTRODUCTION}

The cannabis plant comprises over 104 cannabinoids (ElSohly and Gul, 2014) including $\Delta^{9}$-tetrahydrocannabinol (THC), the primary psychoactive cannabinoid and the one that defines cannabis potency (Izzo et al, 2009). THC binds to the cannabinoid $1\left(\mathrm{CB}_{1}\right)$ receptor, which mediates the positive subjective and reinforcing effects of cannabis (see Cooper and Haney, 2008). Cannabidiol (CBD), by contrast, is a cannabinoid with few if any psychoactive effects (Zhornitsky and Potvin, 2012), and a varied and complex pharmacology. $\mathrm{CBD}$ has low affinity for $\mathrm{CB}_{1}$ and $\mathrm{CB}_{2}$ receptors (Pertwee et al, 2010), binds to $\mathrm{TRPV}_{1,2}$, GPR55, and $5 \mathrm{HT}_{1 \mathrm{a}}$ receptors and inhibits anandamide hydrolysis via FAAH inhibition (Mechoulam et al, 2002; Grotenhermen, 2005; Ryberg et al, 2007). Hashish may contain equal parts

*Correspondence: Professor M Haney, Division on Substance Abuse, New York State Psychiatric Institute and the Department of Psychiatry, Columbia University Medical Center, 1051 Riverside Dr, Unit 120, New York, NY 10032, USA, Tel: +646 774 6153, Fax: +646 774 6I4I, E-mail: mh235@columbia.edu

Received 29 October 2015; revised 18 December 2015; accepted 21 December 2015; accepted article preview online 28 December 2015
CBD and THC (ElSohly et al, 2003; Hardwick and King, 2008; Potter et al, 2008), but CBD is typically present in low concentrations in recreational cannabis $(<0.1 \%)$, based on samples seized by law enforcement.

Yet the effect CBD has, either alone or when combined with THC, is an area of some disagreement. Oral CBD (300-600 mg) alone has been reported to produce mild sedative and anxiolytic effects in some studies (Zuardi et al, 1993; Crippa et al, 2004, 2011; Bergamaschi et al, 2011a,b), whereas most report no measurable psychoactivity (Benowitz et al, 1980; Borgwardt et al, 2008; Bhattacharyya et al, 2009; Winton-Brown et al, 2011; see Niesink and van Laar, 2013). When combined with THC, some have shown that (1) smoked CBD $(150 \mu \mathrm{g} / \mathrm{kg})$ attenuated the 'euphoric' effects of smoked THC $(25 \mu \mathrm{g} / \mathrm{kg}$; Dalton et al, 1976) and (2) oral CBD (1 mg/kg) reduced spontaneous reports of oral THC intoxication (Zuardi et al, 1982). These studies suggested that cannabinoids such as CBD lessen the 'unwanted psychotropic effects' of THC (Stott et al, 2013), and contributed to the rationale for combining THC and CBD for therapeutic use in the form of nabiximols, an oromucosal spray with 1:1 ratio of CBD and THC (Russo and Guy, 2006).

Yet most studies show that neither smoked, vaporized nor oral CBD alters THC's positive subjective effects, such as 
Table I Time-course of Sessions

\begin{tabular}{|c|c|c|c|}
\hline Time & Event & Time & Event \\
\hline \multirow[t]{5}{*}{-150} & Begin session & 60 & Vitals, mood, CRF, MRF \\
\hline & CO, breathalyzer, balance, & & lunch \\
\hline & urine toxicology, pregnancy, & 90 & Vitals, mood, CRF, MRF, tasks \\
\hline & TLFB, C-SSRS, & 120 & Vitals, mood, CRF, MRF \\
\hline & Breakfast & 150 & $\begin{array}{l}\text { Choice: purchase } 0-3 \text { cannabis } \\
\text { puffs }\end{array}$ \\
\hline-120 & $\begin{array}{l}\text { Field sobriety, vitals, mood, } \\
\text { tasks }\end{array}$ & & Vitals \\
\hline-90 & Capsule administration & 160 & Cannabis self-administration \\
\hline-60 & Vitals, CRF & 190 & Vitals, mood, MRF \\
\hline-30 & Vitals, mood, CRF, tasks & 220 & Vitals, mood, MRF \\
\hline-5 & Vitals & 250 & Vitals, mood, MRF \\
\hline 0 & Cannabis administration & 310 & Vitals, mood, CRF, MRF \\
\hline 15 & Vitals, MRF & 325 & Field sobriety \\
\hline 30 & Vitals, mood, CRF, MRF, tasks & & End session \\
\hline
\end{tabular}

Abbreviations: Balance, number of seconds balancing for a maximum of 30 s on each foot; CO, carbon monoxide; CRF, capsule rating form and capsule ID; C-SSRS, Columbia Suicide Severity Rating Scale; Mood Scales, visual analog scale of mood; MRF, cannabis rating form and estimated street value;

Tasks, Digit Symbol Substitution Task and Continuous Performance Task; TLFB, timeline followback; Vitals, blood pressure and heart rate; puffs cost $\$ 0.50 /$ each

feeling 'high' or 'stoned' (Juckel et al, 2007; Roser et al, 2009; Morgan et al, 2010; see Zhornitsy and Potvin, 2012; Hindocha et al, 2015). There are several explanations for this lack of consistency. The varied timing and route of CBD delivery relative to THC likely impacts the outcome. Further, most studies were not designed to directly test $\mathrm{CBD}$ and intoxication and tested only one dose of CBD in combination with one dose of oral THC (dronabinol), so it is difficult to define the nature of the interaction. And few studies have examined CBD's effects on smoked cannabis, the most common route by which THC is administered.

If oral CBD does, in fact, attenuate the positive subjective effects of smoked cannabis, it could have potential to help address the problem of cannabis use disorder (CUD). With increased rates of cannabis use nationwide, and given that $\sim 24 \%$ of patients entering treatment for substance abuse have a diagnosis of CUD (Substance Abuse and Mental Health Services Administration (SAMHSA) and Center for Behavioral Health Statistics and Quality, 2014), there is a clear need to improve treatment outcomes. There are a variety of ways that medications can facilitate drug treatment, and one approach is to reduce the direct positive subjective (eg, cannabis 'liking' or 'good effect') and reinforcing effects (self-administration) of the drug. Thus, the objective of this multi-site, within-subject laboratory study was to assess the influence of a range of CBD doses (0, $200,400,800 \mathrm{mg}$, p.o.) on the reinforcing, subjective, cognitive, and physiological effects of smoked cannabis (0.01 (inactive), $5.30-5.80 \%$ THC) in healthy cannabis smokers.

\section{MATERIALS AND METHODS}

\section{Participants}

Volunteers, 18-50 years of age, were recruited through newspaper advertisements and word of mouth. Those who met inclusion/exclusion criteria after an initial phone screen were invited to the laboratory for further screening. Before enrolling, candidates provided a detailed drug and medical history, received medical and psychiatric evaluations, and signed consent forms detailing all aspects of the research. Participants were accepted into the study if they were healthy, as determined by physical examination, psychiatric screening, electrocardiogram, blood pressure and heart rate, and urine and blood chemistries, were not regular users of drugs other than cannabis (aside from nicotine and caffeine), and were not seeking treatment for their cannabis use. Eligible participants smoked at least half a cannabis cigarette four or more times per week for the 4 weeks before screening, as determined by urine toxicology and self-report. Those who met the Diagnostic and Statistical Manual (of Mental Disorders), fourth edition, revised criteria for Axis 1 conditions that would benefit from medical intervention were also excluded. Females were excluded if they were pregnant or nursing or failing to practice an effective form of birth control. Current use of over-the-counter or prescription medication was also exclusionary.

Participants were told that the study objective was to determine how CBD, an experimental compound not approved by the FDA, influences the effects of cannabis in cannabis smokers. All procedures were approved by the Institutional Review Boards of the New York State Psychiatric Institute, University of Kentucky and Medical University of South Carolina and were in accordance with the Declaration of Helsinki.

\section{Study Design and Procedures}

This within-subject study included eight outpatient sessions over a minimum of eight weeks. Participants completed only one session per week to avoid potential carryover effects resulting from CBD's long terminal half-life (21-33 h; Aguerell et al, 1986; Consroe et al, 1991). Prior to the first laboratory session, participants completed one or two practice sessions during which they were familiarized with the study tasks and procedures (no cannabis or capsules were administered). For experimental sessions, capsules containing placebo or $\operatorname{CBD}(200,400,800 \mathrm{mg})$ were administered, and half of an inactive or active cannabis cigarette was smoked 90 min later. The order of cannabis strength and CBD dose was randomized.

\section{Experimental Sessions}

Table 1 portrays the schedule for experimental sessions, which started at $0900 \mathrm{~h}$ and lasted $\sim 8 \mathrm{~h}$. At the beginning of each session, we conducted a timeline followback questionnaire querying cannabis, alcohol, and other drug use as well as any side-effects or medication use since the last visit. Participants were instructed to refrain from using illicit drugs (other than cannabis, for which no instructions were given) for the duration of the study. They were instructed not to eat, drink alcohol, or smoke cannabis or tobacco cigarettes 
beginning at midnight prior to each session. A urine drug screen, pregnancy test, breath alcohol test, and carbon monoxide test $(\leqslant 9 \mathrm{ppm})$ were conducted at the beginning of each session to confirm compliance. If there was evidence of illicit drug, alcohol or cannabis use on the morning of the session the session was rescheduled.

Participants were given a light breakfast (bagel or cereal, juice, coffee). Following breakfast, baseline cardiovascular measures, subjective effects questionnaires, and performance tasks were completed. CBD or placebo capsules were given 30 min after completion of breakfast. In order to minimize nicotine withdrawal symptoms, tobacco cigarette smokers were given up to two smoking breaks per session scheduled at the same time for all eight sessions. The participant and study staff were blind to capsule content. Ninety minutes after capsule administration, half of a cannabis cigarette was smoked (see below). Cardiovascular and subjective effects measures and a cognitive task battery were completed at baseline and at 15-120 min intervals following capsule and cannabis administration. Participants were allowed to select from a variety of lunch options, including an entree, beverage, and snack 60 min following cannabis administration. To measure the reinforcing effects of cannabis, participants were offered the opportunity to purchase up to three additional 5-s puffs of the cannabis sampled that morning $150 \mathrm{~min}$ after cannabis administration. Each puff cost $\$ 0.50$ of their study earnings. At the end of each session, participants were free to leave after passing field sobriety and balancing tasks.

\section{Study Drugs}

Placebo or CBD (0, 200, 400, 800 mg, STI Pharmaceuticals) capsules in size 00 opaque capsules, prepared by the EMINENT Services Corporation, were administered under double-blind conditions under observation of research staff $90 \mathrm{~min}$ prior to cannabis administration. The broad and upper range of $\mathrm{CBD}$ doses were chosen to ensure pharmacological activity given its known poor oral bioavailability of $<20 \%$ (Mechoulam et al, 2002). Timing of cannabis administration was designed to coincide with time-to-peak $\left(\mathrm{T}_{\max }\right)$ plasma $\mathrm{CBD}$ concentrations estimated at 1-2 h (Agurell et al, 1981; Bhattacharyya et al, 2010; Winton-Brown et al, 2011; Englund et al, 2013).

Cannabis $(0.01,5.30-5.80 \%$ THC; $0.01 \%$ CBD, ca. $800 \mathrm{mg}$ ), provided by the National Institute on Drug Abuse, was administered under single-blind conditions using a cuedsmoking procedure (Foltin et al, 1987). In the morning administration, participants were instructed to light the cigarette' (30s), 'prepare' (5s), 'inhale' (5s), 'hold smoke in lungs' (10s), and 'exhale'. They smoked one puff every minute with a 40-s interval between each puff, until they had smoked $50 \%$ of the cannabis cigarette. In the afternoon, participants were similarly guided through smoking up to three puffs of self-administered cannabis, depending on their choice. Because the color of cannabis leaves varies as a function of THC content (Chait and Pierri 1989), the cannabis was smoked through a cigarette holder and rolled at the end so the cannabis was not visible. Cannabis cigarettes were stored frozen in an airtight container and humidified at room temperature for $24 \mathrm{~h}$ prior to use. The order of cannabis strength and CBD dose were completely randomized.

\section{Assessments}

Subjective Mood and Drug Effects. All subjective effects were measured using visual analog scales, a series of $100-\mathrm{mm}$ long lines labeled 'not at all' at one end $(0 \mathrm{~mm})$ and 'extremely' at the other end $(100 \mathrm{~mm})$. Participants were instructed to rate their subjective experiences according to how they felt at that moment. Measurements were taken at baseline and at scheduled intervals after CBD and cannabis administration (Table 1).

Mood scale. Participants completed a 44-item scale assessing a range of affective and physical symptoms capturing effects, eg, friendly, mellow, sedated, anxious (eg, Haney et al, 2004).

Marijuana rating form. Subjective cannabis-related effects were assessed using a five-item visual analog scale asking participants to rate the strength of the cannabis effect, good effect, bad effect, drug liking, and willingness to smoke the cannabis again. Participants also indicated whether they thought the cannabis was active or inactive.

Capsule rating form. Participants completed a five-item visual analog scale, rating the strength of the drug effect, good effect, bad effect, willingness to take drug again, and drug liking. In addition, participants were asked to indicate whether they thought the capsule was placebo or active.

Performance task battery. Cognitive function was assessed with a computerized battery including a Digit Symbol Substitution Task (DSST; 3 min) and a Continuous Performance Task (CPT: $5 \mathrm{~min})$. This battery, designed for repeated assessments, measures psychomotor speed and sustained and selective attention.

Cardiovascular function. Heart rate and blood pressure were measured at baseline, 30,60, and $85 \mathrm{~min}$ after capsule administration and 15-150 min after cannabis administration.

Plasma CBD. A subset of participants $(n=8)$ at the Columbia University site who completed the eight-week study completed one additional session to assess plasma CBD concentrations following CBD (800 mg) administration. These sessions occurred a minimum of 5 days following the last session day. Sessions began with a breathalyzer, urinalysis, carbon monoxide measure, breakfast, and baseline balance, and then a 20-gauge indwelling catheter (Quik-Cath; Treavenol Laboratories, Deerfield, IL, USA) was placed into a peripheral vein in the arm for blood withdrawal. Baseline blood $(6 \mathrm{ml})$ was drawn and the CBD capsule $(800 \mathrm{mg})$ was administered. Additional samples $(6 \mathrm{ml})$ were collected at 60 , $120,180,240,300$, and $360 \mathrm{~min}$ after CBD administration. Participants were allowed to leave the facility once they passed the field sobriety test. Samples were analyzed by a validated method that uses liquid/liquid extraction, derivitization, and gas chromatography-tandem mass spectrometry (David Moody, $\mathrm{PhD}$ unpublished data). The objective of this measurement was to confirm the bioavailability of the oral CBD doses administered relative to other published studies. 


\section{Data Analysis}

Subjective measures, performance tasks, and cardiovascular measures collected before and after experimenteradministered cannabis were analyzed as (1) time course data using a three-factor repeated measures model (CBD condition, cannabis condition, and time) with an AR (1) covariance structure and (2) peak effect, which was calculated for individual subjects and dose conditions, and analyzed in a two-factor model (CBD condition and $\mathrm{MJ}$ condition) using Proc Mixed in SAS 9.3 (Cary, NC). Although subjective effects and cardiovascular data were also collected after the option to self-administer cannabis, these data were not analyzed because the amount of cannabis self-administered varied across participants. Number of cannabis puffs purchased was analyzed using a two-factor model (CBD condition and MJ condition); the percentage of participants choosing to self-administer cannabis as a function of cannabis strength and CBD dose was analyzed with a McNemar's Test. Tukey's post hoc tests were performed to explore the time course effects and to clarify the effects of individual CBD doses compared with placebo.

Table 2 Demographic Characteristics of Participants

\begin{tabular}{lc}
\hline Number of participants & 31 (I7M; I4F) \\
Race (Black/White/Mixed) & I5/I2/4 \\
Ethnicity (Hispanic/non-Hispanic) & $3 / 28$ \\
Age (years) & $29.1 \pm 9.1$ \\
Cannabis use (\#days/week) & $6.5 \pm 1.0$ \\
Cannabis cigarettes/day & $5.1 \pm 5.3$ \\
Cigarette smokers (\#) & 18 \\
Alcohol drinkers (\#) & 14 \\
\hline
\end{tabular}

Data are presented as means $( \pm S D)$ or as frequency. Alcohol drinkers defined as $\geqslant 1$ drink/week.

\section{RESULTS}

Table 2 describes the demographic information of the research volunteers $(n=31)$ who completed the study. Of note, the sample was heterogeneous in terms of both sex and race. Nineteen additional participants started the study but did not complete it: one was discharged for pregnancy, and another was discharged for both ongoing gastrointestinal (GI) symptoms and inability to comply with the study requirements; the remaining 17 non-completers were unable to adhere to the protocol requirements.

\section{Mood Scale}

Figures 1 and 2 portray mood and cannabis ratings as a function of cannabis strength, CBD dose, and time. Under placebo CBD conditions, active cannabis significantly increased ratings of 'High' (Figure 1) and 'Good Drug Effect' (data not shown) over time (Tukey test, $p<0.001$ ) relative to inactive cannabis. CBD did not significantly alter either of these ratings relative to placebo.

\section{Marijuana Rating Form}

Under placebo CBD conditions, active cannabis significantly increased the ratings of cannabis 'Liking' and 'Strength' (Figure 2), 'Desire to take Again', and 'Good Effect' (data not shown; Tukey test, $p<0.01$ ) relative to inactive cannabis. Active cannabis also increased estimates of the street value of the cannabis smoked relative to inactive cannabis (Figure 2; Tukey test, $p<0.001)$. CBD had no effect on these ratings relative to placebo.

\section{Capsule Rating Form}

Under placebo $\mathrm{CBD}$ conditions, active cannabis did not significantly alter any ratings of the capsule relative to inactive cannabis. There was also no effect of CBD relative to placebo on capsule ratings (data not shown).

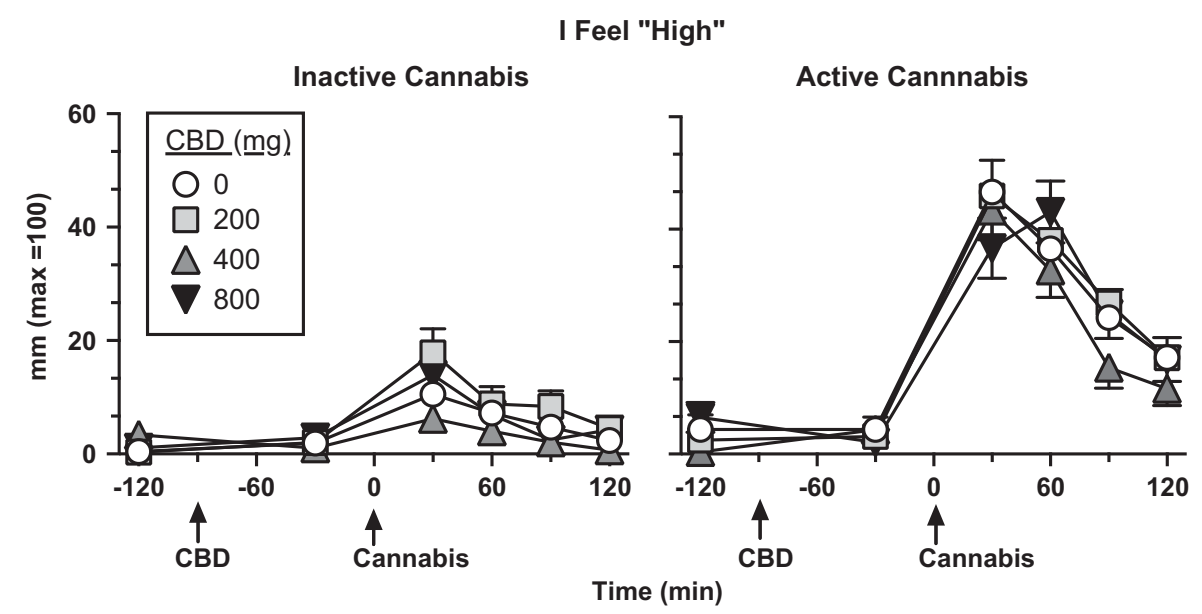

Figure I Effect of inactive (0.0 I\% THC) and active cannabis (5.30-5.80\% THC) as a function of CBD dose and time, beginning at baseline (prior to capsule or cannabis administration) and ending $2 \mathrm{~h}$ after cannabis administration. 'Cannabis' refers to the time in which cannabis (50\% of a NIDA cigarette) was smoked. Error bars represent \pm SEM. 


\section{Task Performance}

Under placebo $\mathrm{CBD}$ conditions, active cannabis did not significantly alter performance on the DSST (eg, percent correct, number attempted, number correct) or CPT (eg, reaction time, number correct, number of misses) relative to
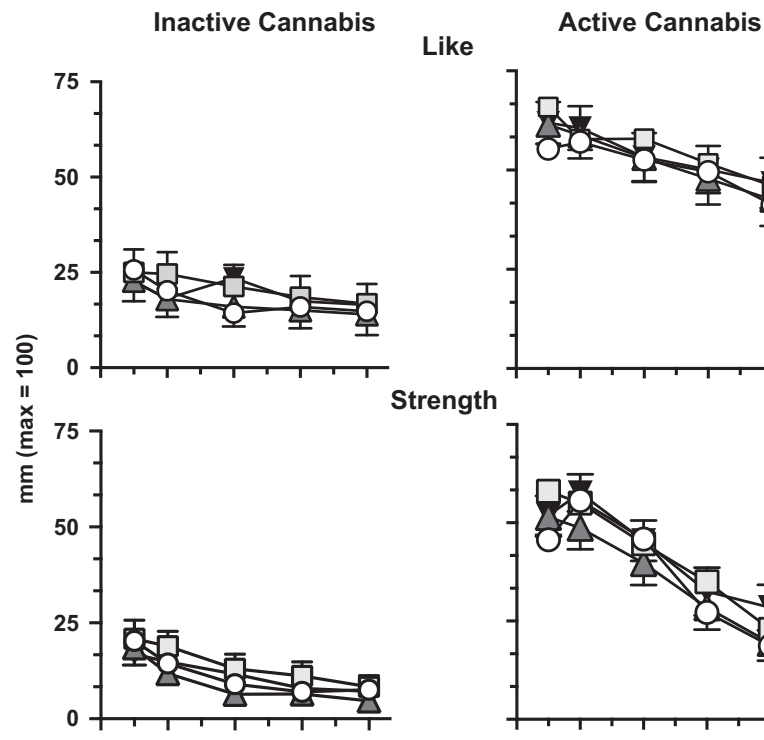

Street Value
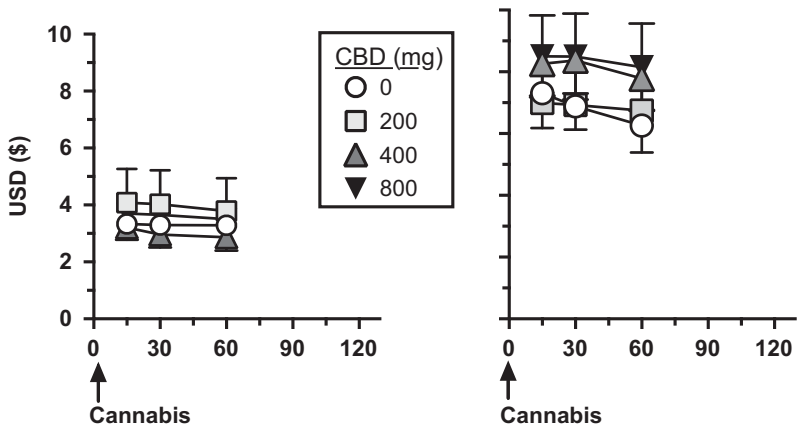

Time $(\min )$

Figure 2 Effect of inactive (0.01\% THC) and active cannabis $(5.30-5.80 \%$ $\mathrm{THC}$ ) as a function of CBD dose and time following cannabis administration. Data were collected for 'Like' and 'Strength' for $2 \mathrm{~h}$ after cannabis administration; street value ratings were collected for I h post cannabis administration. inactive cannabis. There was also no significant effect of CBD relative to placebo on task performance (data not shown).

\section{Cannabis Self-administration}

Figure 3 shows the percentage of participants choosing to self-administer cannabis and the number of inactive and active cannabis puffs purchased as a function of cannabis strength. Under placebo CBD conditions, more participants chose to self-administer active cannabis than placebo cannabis $(p<0.01)$ although difference in the number of active puffs purchased relative to inactive puffs did not reach significance $(p=0.11)$. CBD did not significantly influence either the percentage of participants who chose to self-administer cannabis or the number of puffs self-administered.

\section{Cardiovascular End Points}

Figure 4 shows that under placebo CBD conditions, active cannabis significantly increased peak heart rate $(p<0.01)$, and CBD did not significantly influence this effect relative to placebo. Neither CBD nor cannabis significantly altered systolic or diastolic blood pressure (data not shown).

\section{Medication Side-Effects}

Table 3 shows the frequency of side-effects as a function of CBD dose. GI upset (nausea, vomiting, constipation, gas) and headache were the most frequently cited side-effects, but the overall incidence was low and did not vary with CBD dose.

\section{Plasma CBD}

Figure 5 portrays both mean and individual plasma CBD levels as a function of time following capsule administration (800 mg). As illustrated, there was considerable individual variability in plasma CBD levels, with peak concentrations $\left(\mathrm{C}_{\max }\right)$ ranging from 1.6 to $271.9 \mathrm{ng} / \mathrm{ml}$ (mean: $77.9 \mathrm{ng} / \mathrm{ml}$ ). There was also variability in $\mathrm{T}_{\max }$ ranging from 120 to $360 \mathrm{~min}(\operatorname{mea} n=180 \mathrm{~min})$.

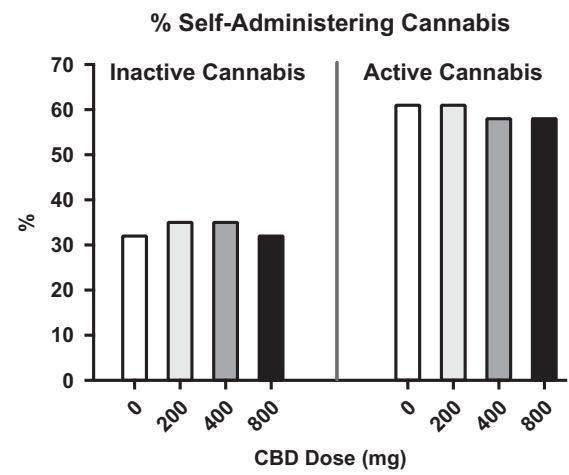

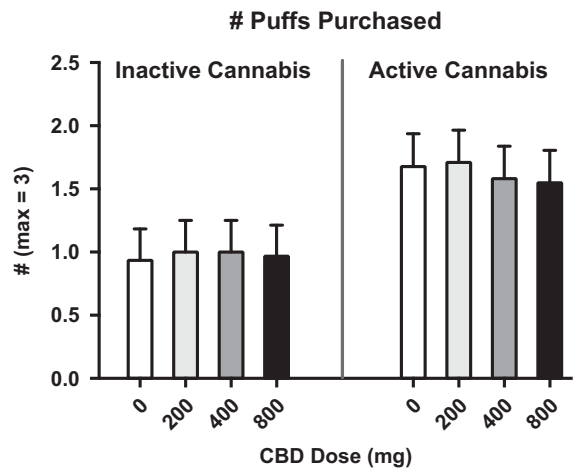

Figure 3 Percentage of participants self-administering inactive $(0.01 \% \mathrm{THC})$ or active $(5.30-5.80 \% \mathrm{THC})$ cannabis, ie, purchasing at least one puff of cannabis available for self-administration ( $\max =$ three puffs) as a function of CBD dose (left figure) and the number of cannabis puffs self-administered as a function of CBD dose. Error bars represent \pm SEM (right figure). 


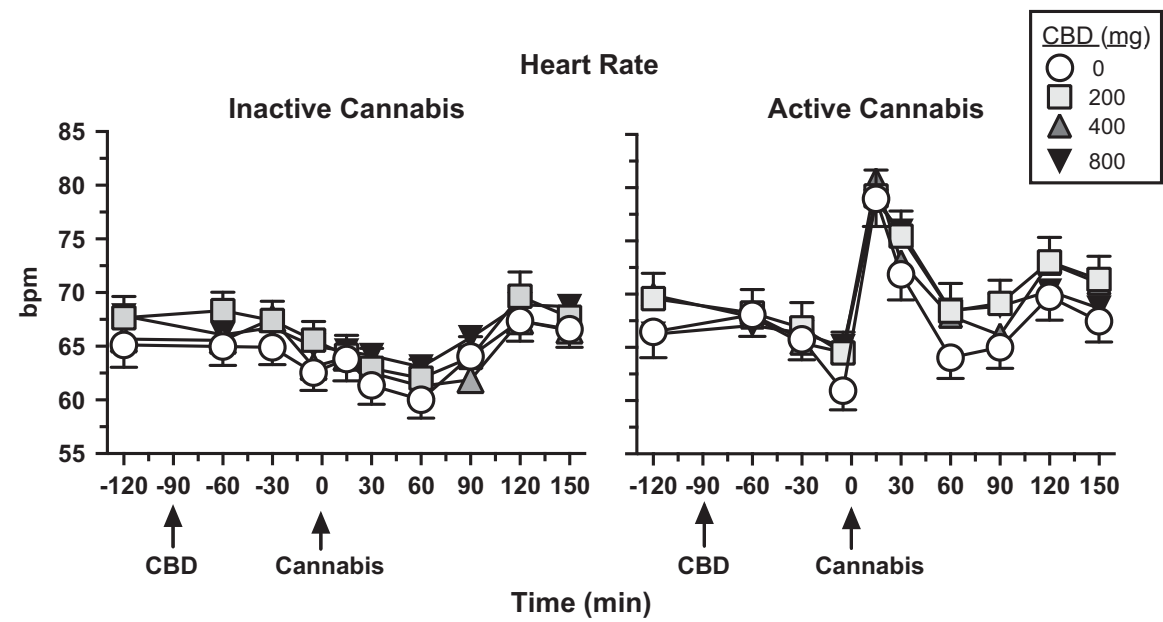

Figure 4 Effect of inactive (0.0 \% THC) and active cannabis (5.30-5.80\% THC) as a function of CBD dose and time, beginning at baseline (prior to capsule or cannabis administration) and ending $2 \mathrm{~h}$ after cannabis administration. Bpm: beats per minute. See Figure I legend for details.

Table 3 Frequency of Side-effects

\begin{tabular}{lcccc}
\hline CBD dose & $\mathbf{0}$ & $\mathbf{2 0 0}$ & $\mathbf{4 0 0}$ & $\mathbf{8 0 0}$ \\
\hline Gastrointestinal upset & 1 & 2 & 1 & 5 \\
Headache & 1 & 1 & 2 & 1 \\
Blurred vision & 2 & 0 & 1 & 1 \\
Anxiety & 1 & 3 & 0 & 0 \\
Fatigue & 0 & 1 & 0 & 1 \\
Cold symptoms & 1 & 0 & 1 & 1 \\
Pain (foot/hand/tooth) & 0 & 2 & 1 & 0 \\
Increased heart rate & 0 & 0 & । & 0 \\
\hline
\end{tabular}

Cannabis strength was collapsed for each CBD dose. Data reflect each time a side-effect was reported within $\leqslant 72 \mathrm{~h}$ following capsule administration across eight sessions $(n=31)$

\section{DISCUSSION}

This multi-site human laboratory study shows that oral CBD pretreatment does not alter the subjective, reinforcing, or cardiovascular effects of smoked cannabis relative to placebo in cannabis smokers. Active cannabis produced significant increases in ratings of 'High' and 'Good Effect' as well as assessments of the cannabis cigarette (eg, 'Strength', 'Liking', 'Desire to take again') and heart rate relative to inactive cannabis. Further, significantly more participants chose to self-administer active cannabis than placebo cannabis. None of these prototypic cannabis effects was affected by CBD relative to placebo.

Oral CBD had slow and variable absorption, consistent with earlier studies. Yet, the absence of any CBD influence on smoked cannabis effects did not appear to reflect poor absorption of the capsules. Mean peak plasma concentrations of CBD $(77.9 \mathrm{ng} / \mathrm{ml})$ following administration of $\mathrm{CBD}(800 \mathrm{mg})$ exceeded those from studies demonstrating a significant CBD effect on mood or fMRI activation. For instance, peak plasma concentrations following administration of CBD $(600 \mathrm{mg})$ administration ranged from $17.0 \mathrm{ng} / \mathrm{ml}$ (Winton-Brown et al, 2011; Bhattacharyya

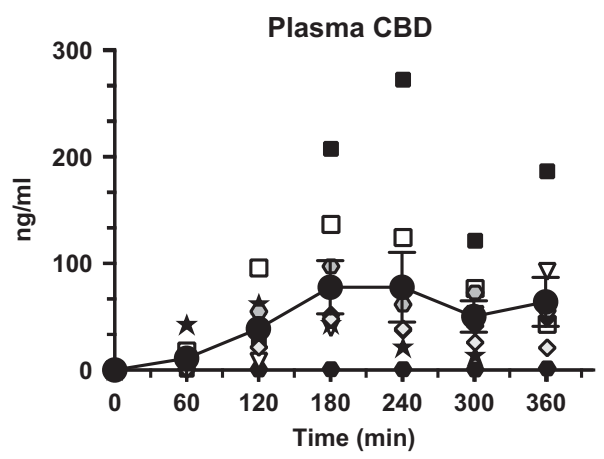

Figure 5 Individual and mean (filled circles, \pm SEM) plasma CBD levels following administration (time $=0 \mathrm{~min}$ ) of $800 \mathrm{mg}$ capsules through $6 \mathrm{~h}$ post dose.

et al, 2010, Borgwardt et al, 2008; Fusar-Poli et al, 2009) to about $55 \mathrm{ng} / \mathrm{ml}$ (Englund et al, 2013). Although cannabis effects peaked $120 \mathrm{~min}$ after $\mathrm{CBD}$ administration in the current study, and 60 min earlier than peak CBD concentrations, there was no indication that $\mathrm{CBD}$ attenuated cannabis effects at any point during the 2-h cannabis time course (Figures 1 and 2); note, we did not assess whether CBD altered the metabolism of THC, as there is little to suggest that this occurs in humans (Hunt et al, 1981; Englund et al, 2013; Agurell et al, 1981; Karschner et al, 2011a,b). Future studies focusing on CBD and THC interactions might consider these considerable individual differences in plasma drug levels following the oral route of administration.

Overall, our findings corroborate studies cited earlier showing that CBD was well tolerated, produced no significant psychoactive or cardiovascular effects relative to placebo when given alone (see Zhornitsky and Potvin, 2012), and that CBD did not alter the effects of i.v., oral, vaporized, or oromucosal THC. For example, the subjective effects of nabiximols (oromucosal spray containing equal parts CBD and THC) did not differ from a comparable dose of oral THC alone (Schoedel et al, 2011; Karschner et al, 2011a,b); CBD 
did not alter ratings of 'stoned' following vaporized THC administration (Hindocha et al, 2015); and, cannabis smoked naturalistically (participant's own self-selected marijuana) with high CBD did not produce different ratings of 'stoned' than cannabis with low CBD concentrations (Morgan et al, 2010). Furthermore, there was no indication that cannabis bred to contain different levels of CBD $(0.2,1.0 \%)$ altered the subjective, physiological, or performance effects of smoked cannabis with varying THC concentrations $(1.8,3.6 \%$ THC; Ilan et al, 2005).

Although CBD does not reduce THC's positive subjective effects (ie, ratings of 'high' or 'stoned'), there is evidence that it may reduce anxiety or transient psychosis-like side-effects of THC observed in infrequent cannabis smokers or when administered alone to patients with anxiety or psychosis (Bhattacharyya et al, 2010; Crippa et al, 2011; Bergamaschi et al, 2011a,b; Leweke et al, 2012; see Niesink and van Laar, 2013). Older studies report that CBD changes the type of psychological reaction induced by THC in infrequent cannabis smokers, reducing their anxiety and thereby rendering THC more enjoyable (eg, Karniol et al, 1974). Daily cannabis smokers rarely have anxiety and psychosis-like symptoms following active cannabis administration, and although there were three instances of anxiety in the present study following cannabis administration, there were too few to assess whether CBD altered these experiences.

Similarly, active cannabis did not worsen cognitive performance in our sample of cannabis smokers relative to inactive cannabis, which likely reflects the development of tolerance (Hart et al, 2001; D'Souza et al, 2008). Preclinical (Wright et al, 2013) and some controlled clinical studies have suggested that CBD reduces THC-related memory impairment (Zhornitsky and Potvin, 2012; Englund et al, 2013). Naturalistic smoking studies, comparing cognitive performance in individuals after they smoked their own cannabis (Morgan et al, 2010) have suggested that CBD protects against the negative cognitive effects of THC (Henquet and Kuepper, 2010). This may be the case but, as others have pointed out (Mechoulam and Parker, 2013; Wright et al, 2013), individuals preferring CBD-rich cannabis may differ at baseline from those who prefer CBD-poor cannabis, suggesting that these findings may reflect group differences rather than CBD concentrations per se.

Thus, in summary, CBD is a cannabinoid with a varied and complex mechanism of action. The present multi-site study, testing a range of $\mathrm{CBD}$ doses using a statistically powerful within-subject design, provides no evidence that acute administration of oral $\mathrm{CBD}$ reduces the reinforcing or positive subjective effects of cannabis in current cannabis smokers. It is possible that chronic rather than acute CBD administration would have produced different results, as the duration of medication administration can have an important impact on outcome in medication development (eg, Haney and Spealman, 2008). It is also possible that different results would have been obtained if $\mathrm{CBD}$ or THC were given by another route of administration or if participants were not cannabis smokers. Nonetheless, the study was designed to determine whether oral CBD pretreatment has potential to be a treatment medication for CUD, and the answer to that question appears to be no.

\section{FUNDING AND DISCLOSURE}

The authors declare no conflict of interest.

\section{ACKNOWLEDGMENTS}

This research was supported by the US National Institute on Drug Abuse (DA009236, U10DA013727, U10DA13732). We also thank NIDA for supplying the cannabis to conduct this study, and Dr Hari Singh, PhD at NIDA for facilitating the analysis of plasma CBD concentrations by Dr David Moody, $\mathrm{PhD}$ at University of Utah (NIDA contract \#NO1DA-14-7788). Many thanks to Dr Richard W Foltin (CUMC) and Dr Thomas H Kelly (UK) for their support in conducting this study, and to the expert contributions of Dr Adam Bisaga, Olivia Derella (CUMC), Dr Samy Claude Elayi, Tori Votaw, and Cleeve Emurian (UK). This research was funded by NIDA. Dr Haney has received research support from Aelis Farma and Lifeloc Technologies, and along with Dr Cooper, has received research support from investigator-initiated studies from Insys Therapeutics. Dr Cooper serves as a consultant to KannaLife Sciences and PharmaCann, LLC. Dr McRae-Clark has received research support from Forest Pharmaceuticals (medication only). Dr Gray has received research funding from Supernus Pharmaceuticals and Merck, for unrelated research.

\section{REFERENCES}

Agurell S, Carlsson S, Lindgren J, Ohlsson A, Gillespie H, Hollister L (1981). Interactions of $\Delta 11$-tetrahydrocannabinol with cannabinol and cannabidiol following oral administration in man. Assay of cannabinol and cannabidiol by mass fragmentographywith cannabinol and cannabidiol following oral administration in man. Assay of cannab. Experientia 37: 1090-1092.

Agurell S, Haldin M, Lindgren J, Ohlsson A, Widman M, Gillespie $\mathrm{H}$ et al (1986). Pharmacokinetics and metabolism of delta 1-tetrahydrocannabinol and other cannabinoids with emphasis on man. Pharmacol Rev 38: 21-43.

Benowitz NL, Nguyen T, Jones RT, Herning R, Bachman J (1980). Metabolic and psychophysiologic studies of cannabidiolhexobarbital interaction. Clin Pharmacol Ther 28: 115-120.

Bergamaschi M, Queiroz R, Chagas M, Oliveira D, Martinis B, Kapczinski F et al (2011a). Cannabidiol reduces the anxiety induced by simulated public speaking in treatment-naïve social phobia patients. Neuropsychopharmacology 36: 1219-1226.

Bergamaschi M, Queiroz R, Zuardi A, Crippa J (2011b). safety and side effects of cannabidiol, a cannabis sativa constituent. Curr Drug Safety 6: 237-249.

Bhattacharyya S, Fusar-Poli P, Borgwardt S, Martin-Santos R, Nosarti C, O'Carroll C et al (2009). Modulation of Mediotemporal and Ventrostriatal Function in Humans by $\Delta 9$-Tetrahydrocannabinol. Arch Gen Psychiatry 66: 442-442.

Bhattacharyya S, Morrison PD, Fusar-Poli P, Martin-Santos R, Borgwardt S, Winton-Brown T et al (2010). Opposite effects of $\Delta$-9-tetrahydrocannabinol and cannabidiol on human brain function and psychopathology. Neuropsychopharmacology 35: 764-774.

Borgwardt S, Allen P, Bhattacharyya S, Fusar-Poli P, Crippa JA, Seal ML et al (2008). neural basis of $\Delta$-9-tetrahydrocannabinol and cannabidiol: effects during response inhibition. Biol Psychiatry 64: 966-973.

Chait LD, Pierri J (1989). Some physical characteristics of NIDA marijuana cigarettes. Addict Behav 14: 61-67. 
Consroe P, Laguna J, Allender J, Snider S, Stern L, Sandyk R et al (1991). Controlled clinical trial of cannabidiol in Huntington's Disease. Pharmacol Biochem Behav 40: 701-708.

Cooper ZD, Haney M (2008). Cannabis reinforcement and dependence: Role of the cannabinoid CB1 receptor. Addict Biol 13: 188-195.

Crippa J, Derenusson GN, Ferrari TB, Wichert-Ana L, Dura F, Marti N-Santos RO et al (2011). Neural basis of anxiolytic effects of cannabidiol (CBD) in generalized social anxiety disorder-a preliminary report. J Psychopharmacol 25: 121-130.

Crippa JA, Zuardi AW, Garrido GE, Wichert-Ana L, Guarnieri R, Ferrari L et al (2004). Effects of Cannabidiol (CBD) on Regional Cerebral Blood Flow. Neuropsychopharmacology 29: 417-426.

Dalton WS, Martz R, Lemberger L, Rodda BE, Forney RB (1976). Influence of cannabidiol on delat-9-tetrahydrocannabinol effects. Clin Pharmacol Ther 19: 300-309.

D'Souza DC, Ranganathan M, Braley G, Gueorguieva R, Zimolo Z, Cooper $\mathrm{T}$ et al (2008). Blunted psychotomimetic and amnestic effects of delta-9-tetrahydrocannabinol in frequent users of cannabis. Neuropsychopharmacology 33: 2505-2516.

ElSohly M, Gul W (2014). Constituents of cannabis sativa. In: Pertwee Roger G (ed). Handbook of Cannabis. Oxford University Press: New York, NY, USA, pp 3-22.

ElSohly M, Wachtel S, Wit H (2003). Cannabis versus THC: response to Russo and McPartland. Psychopharmacology 165: 433-434.

Englund A, Morrison PD, Nottage J, Hague D, Kane F, Bonaccorso S et al (2013). Cannabidiol inhibits THC-elicited paranoid symptoms and hippocampal-dependent memory impairment. J Psychopharmacology 27: 19-27.

Foltin RW, Brady JV, Fischman MW, Emurian CS, Dominitz J (1987). Effects of smoked cannabis on social interaction in small groups. Drug Alcohol Depend 20: 87-93.

Fusar-Poli P, Crippa JA, Bhattacharyya S, Borgwardt SJ, Allen P, Martin-Santos $R$ et al (2009). Distinct effects of $\Delta 9$-tetrahydrocannabinol and cannabidiol on neural activation during emotional processing. Arch Gen Psychiatry 66: 95-105.

Grotenhermen F (2005). Cannabinoids. Curr Drug Targets CNS Neurol Disord 4: 507-530.

Haney M, Hart CL, Vosburg SK, Nasser J, Bennet A, Zubaran C et al (2004). Marijuana withdrawal in humans: effects of oral THC or divalproex. Neuropsychopharmacology 29: 158-170.

Haney M, Spealman R (2008). Controversies in translational research: drug self-administration. Psychopharmacology 199: 403-419.

Hardwick S, King LA (2008). Home Office Cannabis Potency Study. Home Office Scientific Development Branch: St Albans. Report.

Hart C, Van Gorp W, Haney M, Foltin R, Fischman M (2001). effects of acute smoked marijuana on complex cognitive performance. Neuropsychopharmacology 25: 757-765.

Henquet C, Kuepper R (2010). Does cannabidiol protect against the negative effects of THC? Br J Psychiatry 197: 259-260.

Hindocha C, Freeman T, Schafer G, Gardener C, Das R, Morgan C et al (2015). Acute effects of delta-9-tetrahydrocannabinol, cannabidiol and their combination on facial emotion recognition: a randomised, double-blind, placebo-controlled study in cannabis users. Eur Neuropsychopharmacol 25: 325-334.

Hunt C, Jones R, Herning R, Bachman J (1981). Evidence that cannabidiol does not significantly alter the pharmacokinetics of tetrahydrocannabinol in man. J Pharmacokinetics Biopharmaceutics 245-260.

Ilan A, Gevins A, Coleman M, Elsohly M, Wit H (2005). Neurophysiological and subjective profile of marijuana with varying concentrations of cannabinoids. Behav Pharmacol 16: 487-496.

Izzo A, Borrelli F, Capasso R, Di Marzo V, Mechoulam R (2009). non-psychotropic plant cannabinoids: new therapeutic opportunities from an ancient herb. Trends Pharmacol Sci 30: 515-527.
Juckel G, Roser P, Nadulski T, Stadelmann A, Gallinat J (2007). Acute effects of $\Delta 9$-tetrahydrocannabinol and standardized cannabis extract on the auditory evoked mismatch negativity. Schizophr Res 97: 109-117.

Karniol I, Shirakawa I, Kasinski N, Pfeferman A, Carlini E (1974). Cannabidiol interferes with the effects of $\Delta 9$-tetrahydrocannabinol in man. Eur J Pharmacol 28: 172-177.

Karschner E, Darwin W, Goodwin R, Wright S, Huestis M (2011a). Plasma cannabinoid pharmacokinetics following controlled oral 9-tetrahydrocannabinol and oromucosal cannabis extract administration. Clin Chem 57: 66-75.

Karschner E, Darwin W, Mcmahon R, Liu F, Wright S, Goodwin R et al (2011b). Subjective and physiological effects after controlled sativex and oral the administration. Clin Pharmacol Ther Clin Pharmacol Ther 89: 400-407.

Leweke FM, Piomelli D, Pahlisch F, Muhl D, Gerth CW, Hoyer C et al (2012). Cannabidiol enhances anandamide signaling and alleviates psychotic symptoms of schizophrenia. Transl Psychiatry 2: E94.

Mechoulam R, Parker L (2013). Towards a better cannabis drug. $\mathrm{Br}$ J Pharmacol 170: 1363-1364.

Mechoulam R, Parker L, Gallily R (2002). cannabidiol: an overview of some pharmacological aspects. J Clin Pharmacol 42: 11S-19S.

Morgan C, Freeman T, Schafer G, Curran H (2010). Cannabidiol attenuates the appetitive effects of $\Delta 9$-tetrahydrocannabinol in humans smoking their chosen cannabis. Neuropsychopharmacology 1879-1885.

Niesink RJ, van Laar MW (2013). Does cannabidiol protect against adverse psychological effects of THC? Front Psychiatry 4: 130.

Pertwee RG, Howlett AC, Abood ME, Alexander SP, Di Marzo V, Elphick MR et al (2010). International union of basic and clinical pharmacology. LXXIX. Cannabinoid receptors and their ligands: beyond CB1 and CB2. Pharmacol Rev 62: 588-631.

Potter DJ, Peter C, Brown MB (2008). Potency of D9-THC and other cannabinoids in cannabis in England in 2005: implications for psychoactivity and pharmacology. J Forensic Sci 53: 90-94.

Roser P, Gallinat J, Weinberg G, Juckel G, Gorynia I, Stadelmann A (2009). Psychomotor performance in relation to acute oral administration of $\Delta 9$-tetrahydrocannabinol and standardized cannabis extract in healthy human subjects. Eur Arch Psychiatry Clin Neurosci 259: 284-292.

Russo EB, Guy GW (2006). A tale of two cannabinoids: the therapeutic rationale for combining tetrahydrocannabinol and cannabidiol. Med Hypotheses 66: 234-246.

Ryberg E, Larsson N, Sjögren S, Hjorth S, Hermansson N, Leonova J et al (2007). The orphan receptor GPR55 is a novel cannabinoid receptor. Br J Pharmacol 152: 1092-1101.

Schoedel K, Chen N, Hilliard A, White L, Stott C, Russo E et al (2011). A randomized, double-blind, placebo-controlled, crossover study to evaluate the subjective abuse potential and cognitive effects of nabiximols oromucosal spray in subjects with a history of recreational cannabis use. Hum Psychopharmacol 26: 224-236.

Stott CG, White L, Wright S, Wilbraham D, Guy GW (2013). A phase I study to assess the single and multiple dose pharmacokinetics of THC/CBD oromucosal spray. Eur J Clin Pharmacol 69: 1135-1147.

Substance Abuse and Mental Health Services Administration (SAMHSA), Center for Behavioral Health Statistics and Quality (2014). Treatment Episode Data Set (TEDS) 2002-2012 National Admissions to Substance Abuse Treatment Services. BHSIS Series S-71, HHS Publication No. (SMA) 14-4850.

Winton-Brown TT, Allen P, Bhattacharyya S, Borgwardt SJ, Fusar-Poli P, Crippa JA et al (2011). Modulation of auditory and visual processing by delta-9-tetrahydrocannabinol and cannabidiol: an fmri study. Neuropsychopharmacology 36: $1-9$. 
Wright MJ Jr, Vandewater SA, Taffe MA (2013). Cannabidiol attenuates deficits of visuospatial associative memory induced by $\Delta(9)$ tetrahydrocannabinol. $\mathrm{Br} J$ Pharmacol 170: 1365-1373.

Zhornitsky S, Potvin S (2012). Cannabidiol in humans-the quest for therapeutic targets. Pharmaceuticals (Basel) 5: 529-552.
Zuardi A, Cosme R, Graeff F, Guimarães F (1993). Effects of ipsapirone and cannabidiol on human experimental anxiety. J Psychoparmacol 7: 82-88.

Zuardi AW, Shirakawa I, Finkelfarb E, Karniol IG (1982). Action of cannabidiol on the anxiety and other effects produced by D9-THC in normal subjects. Psychopharmacology 76: 245-250. 